\title{
A POPULATION OF LYCHNOPHORA ERICOIDES MART. (ARNICA) (ASTERACEAE) IS PRONE TO EXTINCTION IN A SAVANNA OF CENTRAL BRAZIL
}

\author{
S. Ribeiro-Silva ${ }^{1}$, M. B. Medeiros' 2 , V. V. F. Lima ${ }^{2}, A$. B. Giroldo ${ }^{3}$, \\ S. E. DE NORONHA ${ }^{2} \&$ F. O. RESENDE ${ }^{1}$
}

Lychnophora ericoides Mart. (Asteraceae), popularly known as arnica, is a plant species subjected to non-timber forest products extraction. Evidence is mounting that some local populations are on the brink of extinction. However, demographic studies of Lychnophora ericoides are rare. Therefore, as a step towards conservation, a remnant population of Lychnophora ericoides located in an area of the Cerrado (Brazilian Savanna) in Central Brazil was evaluated from 2010 through 2014. Disturbances such as wildfires and harvesting of Lychnophora ericoides were randomly distributed throughout the study period in this area. Four annual transition matrices $(A 1, A 2, A 3$ and $A 4)$ were constructed, based on life stages. The main results of studies of population dynamics for this species are as follows: 1 ) population growth rates $(\lambda)$ with $95 \%$ confidence intervals indicated a declining population in all periods from 2010 to 2014; 2) stochastic population growth rate considering the four matrices was $<1$ with value $\lambda=0.358$ and $\left.\mathrm{CI}_{95 \%}=(0.354-0.362) ; 3\right)$ survival with permanence at the same stage of reproductive adult individuals (46-80\%) contributed most to population growth rate, based on elasticity analysis; 4) the population is much less likely to have increases in density, compared with reduction, for all intervals from 2010 to 2014, based on transient indices; 5 ) the low value of $\lambda$ in the high-mortality year was caused by lower stasis of individuals in the seedling or sapling and juvenile life stages, as well as fecundity in the 2011-2012 and 2012-2013 intervals, as shown by a life table response experiment; and 6) 100\% of the population will probably be extinct within 15 years. There is evidence that the main cause for local extinction of Lychnophora ericoides could be the effects of frequent wildfires. Based on these results, it is suggested that the time has come for significant conservation efforts to rescue this population, including monitoring, protection and education as the first steps towards protection of this vulnerable plant species.

Keywords. Demography, life table response experiment, matrix population models, population growth rate, transient dynamics, wildfires.

1 Centro Nacional de Avaliação da Biodiversidade e de Pesquisa e Conservação do Cerrado, Instituto Chico Mendes; Prédio do Centro de Excelência do Cerrado; Jardim Botânico de Brasília, SMDB Conjuncto 12, Lago Sul, Brasília DF, Brazil. E-mail for correspondence: suelma.ribeirosilva@gmail.com

2 Embrapa Recursos Genéticos e Biotecnologia, Parque Estação Biológica, Avenida W5 Norte, DF 70770917, Brasília, Brazil.

3 Universidade de Brasília, Departamento de Ecologia, Campus Universitário Darcy Ribeiro, Brasília, DF 70910-900, Brazil. 


\section{INTRODUCTION}

Based on many studies, it has been concluded that the current levels and intensities of harvesting of most plant species subjected to non-timber forest products (NTFPs) extraction do not threaten their natural populations. Furthermore, it has been found that plant species subjected to NTFPs extraction may, in fact, represent an attractive option for keeping gatherers out of poverty (Stanley et al., 2012).

However, some studies have also reached the conclusion that extraction and trade of some plant species subjected to NTFPs extraction may cause overharvesting, which leads to population declines and biodiversity losses (Vasquez \& Gentry, 1989; Gaoue \& Ticktin, 2010). Also, most ecological analyses of plant population sustainability report physical extraction rates over a short study period, usually 2 years or less (Stanley et al., 2012). Hence, long-term ecological monitoring is essential to evaluate the effects of episodic recruitment, periodic disturbances and harvesting intensity on plant species (Ticktin, 2004; Stanley et al., 2012).

Lychnophora ericoides Mart. is a shrub popularly known in Brazil as arnica, false arnica, Brazilian arnica, arnica da Serra, candeia and pau candeia (Almeida et al., 1998; Semir et al., 2011). As a plant species sold over the course of the past 30 years at fairs and pharmacies, the species is a culturally important plant in Brazil (Semir et al., 2011). The lack of polymorphism, low migration and disjunct geographical distribution with small populations of Lychnophora ericoides (Collevatti et al., 2009) are among the factors that strengthen the possibility of population declines. Also, the intensive harvesting of leaves and branches of Lychnophora ericoides may cause high individual mortality (Silva, 2005).

Demographic studies are fundamental to understanding the effects of harvesting on the population dynamics of plant species (Ticktin et al., 2002; Zuidema \& Boot, 2002; Gaoue \& Ticktin, 2010). Matrix population models (MPMs) have been widely used as a tool to assess the population dynamics of plants, including the effects of NTFPs harvesting on population dynamics (Bernal, 1998; Zuidema \& Boot, 2002; Holm et al., 2008; Portela et al., 2010; Baldauf et al., 2015). Schmidt et al. (2011) reviewed studies that used MPMs to evaluate species subjected to NTFPs extraction and observed that whole-plant harvest of herbs and bark harvest from trees was not sustainable, largely because of decreases in survival of individuals, whereas palm leaf or fruit harvest and rattan stem harvest were potentially sustainable.

Schmidt et al. (2011) also emphasised the need to collect data on environmental or management covariates that could potentially have an important effect on population dynamics (e.g. rainfall, fire or grazing). Gauoe \& Ticktin (2010) found that ecological differences between regions had a more significant effect on population growth rates of African mahogany (Khaya senegalensis (Desv.) A.Juss.) than harvest practices. Baldauf et al. (2015) observed high mortality in many diameter classes of the NTFP species Himatanthus drasticus (Mart.) Plumel correlated with the extremely low precipitation levels in a Brazilian semiarid region, and Ticktin et al. (2012) observed that invasive 
species, besides grazing, are the main drivers of declines of amla (Phyllanthus emblica L. and Phyllanthus indofischeri Bennet).

We predict that disturbances occurring frequently in Cerrado remnants, such as wildfires, rainfall variability and harvesting, would have negative effects on the population growth rates of Lychnophora ericoides, and that these are the main factors strengthening the possibility of population declines. The alternative hypothesis is null effects on the population growth rates of Lychnophora ericoides.

In matrix population modeling, if a population experiences a constant environment with unlimited resources, then it settles to a long-term stable rate of asymptotic growth (or decline) and a theoretically stable demographic distribution. However, populations typically experience a changeable environment in which extrinsic disruptions to population structure of biotic, abiotic and anthropogenic origin lead to a realised initial demographic distribution that is different from the population's stable demographic distribution (Stott et al., 2011). An alternative approach for evaluating population dynamics comprises the indices of transient dynamics, which describe how much populations vary as a consequence of stochastic events before reaching asymptotic growth rates and stable-stage distributions (Stott et al., 2011, 2012).

Accordingly, this article reports the results of a demographic study of a remnant population of Lychnophora ericoides in the Central Brazilian Cerrado (Brazilian Savanna). The study was carried out with the aim of using MPMs to analyze the demographic trends of this species from 2010 to 2014, in the expectation that the results of measurement of population asymptotic growth rates and transient dynamics, a life table response experiment (LTRE) and calculation of probability of local extinction could form a basis for the biological conservation of this species. Furthermore, we have collected temporal data on environmental drivers, such as rainfall patterns and the fire regime, as well as personal observations related to management activities (harvesting) that could potentially have important effects on the population dynamics of Lychnophora ericoides.

\section{Materials and Methods}

Study area and species description

The Federal District is located in the Central-West Region of Brazil $\left(47^{\circ} 25^{\prime}-48^{\circ} 12^{\prime}\right.$ longitude and $15^{\circ} 30^{\prime}-16^{\circ} 03^{\prime}$ latitude). Elevation varies from 1000 to $1152 \mathrm{~m}$ above sea level.

The present study was carried out in an area of campo rupestre at Sucupira Farm, which is located in the south-western city of Brasília, Federal District. Sucupira Farm occupies an area of 1736 ha. Campo rupestre is a herbaceous-shrubby vegetation type of the Cerrado, that occurs at altitudes higher than $700 \mathrm{~m}$ and usually on litholic soils, where species of the genus Lychnophora are frequent, along with other members of the Asteraceae (Ribeiro \& Walter, 2008). 
The climate in this region is classified as Aw, in accordance with the Köppen climate classification system, which means wet tropical with two well-marked climatic seasons (dry winters and wet summers). The annual rainfall is from 1300 to $1800 \mathrm{~mm}$, and the mean annual temperature ranges from 23 to $25^{\circ} \mathrm{C}$ (Silva et al., 2008).

The Brazilian Institute of the Environment and Renewable Natural Resources (Instituto Brasileiro do Meio Ambiente e dos Recursos Naturais Renováveis) listed Lychnophora ericoides as a threatened species (portaria no. 37-N, 3 April 1992). Currently, this species is not included in national or international lists of threatened species. However, the disjunct geographical distribution with small populations (Collevatti et al., 2009) and the traditional and extensive trade of this species as an NTFP (Semir et al., 2011) are factors that indicate that it should not have been excluded from such lists.

Lychnophora ericoides occurs in the Cerrado rocky environments (campos rupestres), which are habitats characterised by shallow soils, low nutrients, high levels of aluminium, and seasonal water deficiency, in which plants are subjected to high solar exposure, strong winds and a wide daily thermal amplitude (Benites, 2001; Benites et al., 2007). The flowering of Lychnophora ericoides occurs between July and early October and from January to mid-March, with a peak in February, and may be very asynchronous between individuals. Lychnophora ericoides is mainly pollinated by butterflies, bees (Apidae) and wasps (Scoliidae) (Avelino, 2005). The presence of 3-5 flowers on each floral bud confers adaptation against predation, because up to $70 \%$ of the floral buds are free of infestation (Avelino, 2005).

Similar to other Cerrado woody species, Lychnophora ericoides has thick bark, densely packed persistent leaf bases and a sprouting capacity after fires, all of which afford resilience and resistance to Cerrado wildfires, typically occurring at 3- to 5-year intervals (Gottsberger \& Silberbauer-Gottsberger, 2006). However, high fire frequency (annual fires) of anthropogenic origin, as observed in the study area, results in both mortality of woody species individuals and a high proportion of plants suffering top kill (aerial mortality) (Medeiros \& Miranda, 2005).

This area in Sucupira Farm harbours one of the few populations of Lychnophora ericoides in the Federal District, and it has been harvested periodically. Harvesters prune aerial parts (Fig. 1) without authorisation from Sucupira Farm, the responsible management entity. An important way to test the direct effects of NTFPs harvest is to take the potential for spatiotemporal variation into account in the study design (Schmidt et al., 2011). However, the illegal nature of harvesting activities in the area has prevented the establishment of controlled areas, and it was possible to include only temporal variation in the study design. Harvesting of stems, leaves and branches was annual throughout the study period. Although this activity occurred in different months from 2010 to 2014, it intensified in the period from 2013 to 2014 (personal observation). Despite the number of harvested individuals in the sampled plots not being recorded because harvesters prune the aerial parts furtively as an illegal activity, a number of individuals disappeared in this period. These individuals vanished in the study area, and even the numbered metal identification tags disappeared. Field 


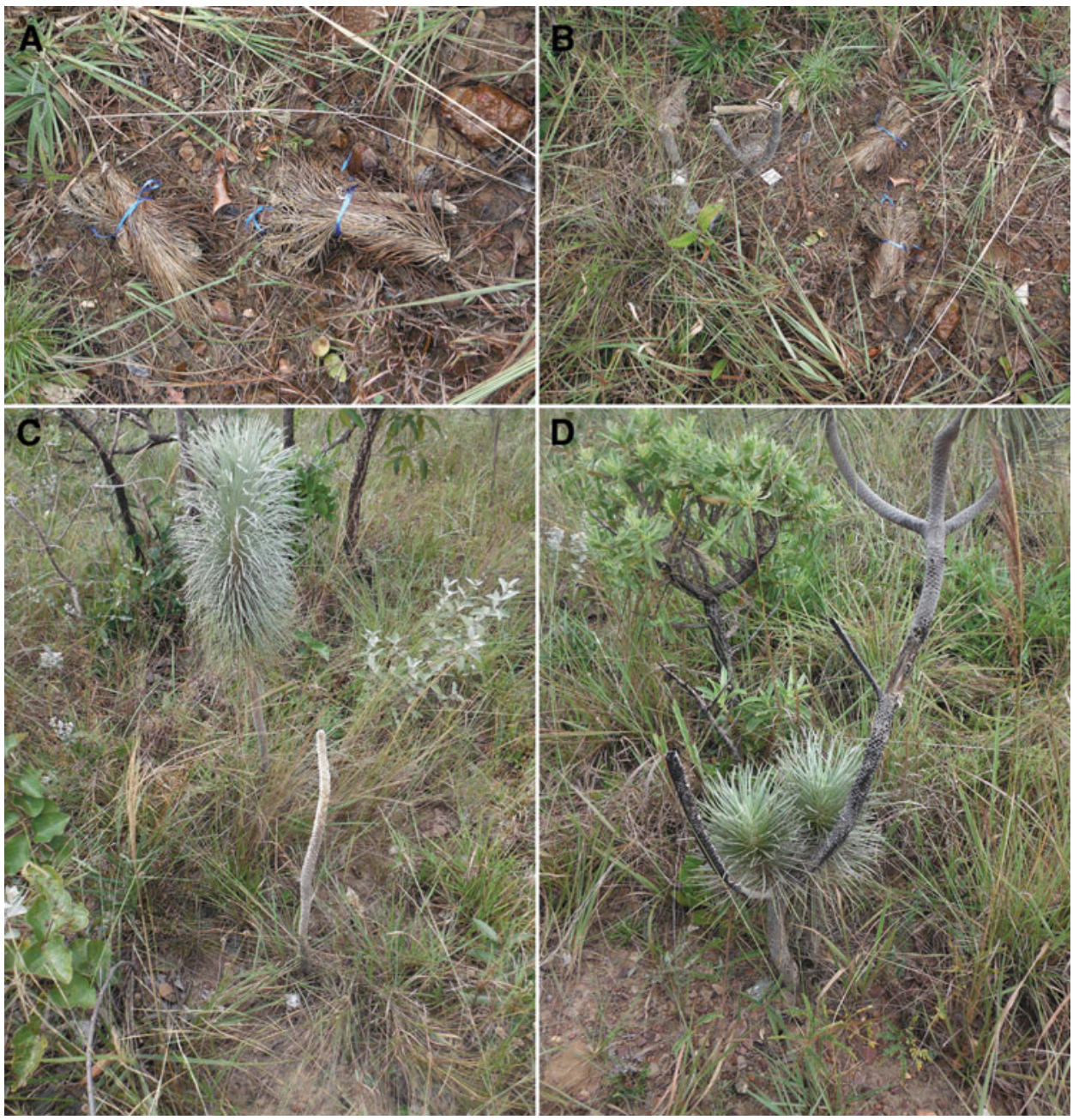

FIG. 1. Branches of Lychnophora ericoides tied for marketing (A and B), harvested branches (C) and individuals with evidence of damage caused by fire (D). (Photographs by Felipe Oliveira Resende.)

observations indicated that individuals were generally harvested after data collection (February to March), during and after the population's reproductive phase. There are no grazing activities or invasive species in this study area.

\section{Fire regime and rainfall}

To determine the frequency of fire scars, we counted scars from 2000 to 2014 using LandSat with $30 \mathrm{~m}$ of spatial resolution (TM 5, 7 ETM and 8 OLI) satellite images obtained from the United States Geological Service (2015) with false-color composition R4G5B3 (Landsat TM 5 and ETM 7) and R5G6B4 (Landsat 8 OLI) 


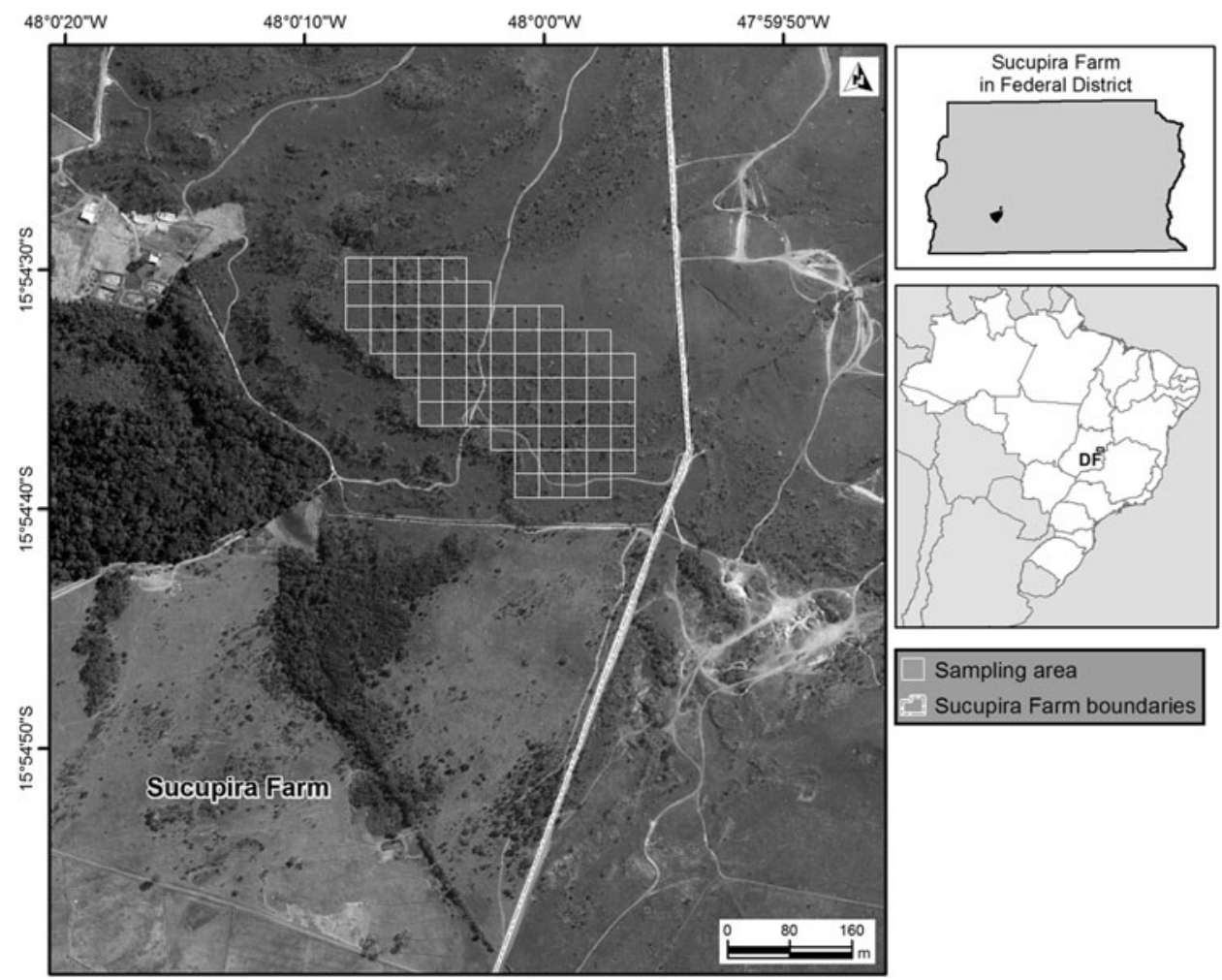

FIG. 2. Sampling grid in campo rupestre for individuals of Lychnophora ericoides at Sucupira Farm, Brasília, Federal District, Brazil.

(Giroldo \& Scariot, 2015). We selected satellite images from June to October in each year relative to the dry season. The processing of the images was done with ESRI ArcGIS, version 10.1

The annual rainfall values from 2010 to 2013 were obtained from the INMET database from a weather station (Brasília) located $30 \mathrm{~km}$ from the study site (Instituto Nacional de Meterologia, continuously updated).

\section{Annual samplings}

All Lychnophora ericoides individuals existing in the study area were evaluated in a grid of 69 contiguous plots each measuring $20 \times 20 \mathrm{~m}$ (Fig. 2). Individuals were identified with aluminium tags between January 2010 and February 2014. Height and stem diameter $(\mathrm{mm})$ at ground level were measured using a metric tape and a digital caliper, respectively. The study included four demographic intervals: 2010-2011, 2011-2012, 2012-2013 and 2013-2014. Survival of the plants was monitored between January and February of each annual interval. 


\section{Population projection matrices}

Four annual transition matrices $(A 1, A 2, A 3$ and $A 4)$ were constructed, based on life stages (Lefkovitch, 1965). The Lychnophora ericoides population was classified into three life stages: seedling or sapling, juvenile and adult. Classification was based on size and reproductive status: seedlings or saplings (plants up to $20 \mathrm{~mm}$ in diameter), juveniles ( $>20$ to $28 \mathrm{~mm}$ in diameter) and adults ( $>28 \mathrm{~mm}$ in diameter; reproductive individuals). The size of individuals with flowers or fruits (reproductive individuals) was observed throughout the study period.

To construct these matrices, we used the following parameters from the survey for each time interval $t$ and $t+1$ : stasis, growth and retrogression. Fecundity $(F)$ was calculated as the number of recruited plants between the time interval $t$ and $t+1$ divided by the number of adult individuals. The construction of the Lefkovitch matrix and its analysis are described by Caswell (2001).

\section{Matrix population models and population dynamics}

The population growth rate (dominant eigenvalue, $\lambda$ ) with $95 \%$ confidence interval was calculated by the bootstrap method, resampling the data 10,000 times (Caswell, 2001).

The stochastic population growth rate $(\exp [\log (\lambda s)])$ was performed with 10,000 simulations (T) and a confidence interval of $95 \%$ (Morris \& Doak, 2002) to evaluate the effects of environmental variability on population dynamics. Each matrix was estimated with a probability of $0.30 \%$, and the 2013-2014 matrix with a probability of $0.10 \%$ because of the extremely high mortality of individuals in this period. Elasticity analyses were performed to characterise the relative contribution of each matrix element (aij) to the population growth rates (Caswell, 2001; Kroon et al., 2000).

The cumulative distribution function was also calculated for the predicted extinction time of the Lychnophora ericoides population through simulations of probability in a stochastic environment for the time intervals noted above (Morris \& Doak, 2002). Each matrix had equal probability of occurrence (30\%), again excluding the $2013-$ 2014 matrix with a probability of $10 \%$, for a maximum time of 50 years, with 10 simulations of the cumulative distribution function. The cut-off limit (threshold) of quasi-extinction was 50 individuals.

\section{Transient dynamics}

We used the indices that measure transient (short-term) dynamics to complement the demographic parameters based on long-term population growth rates (Stott et al., 2011, 2012): damping ratio (a measure of the speed at which the population converges to stability), reactivity (maximum population growth in a single time step, relative to stable growth rate), first-time step attenuation (minimum population growth in a single time step, relative to stable growth rate), maximum amplification (the largest possible future population density achievable, relative to a population with stable growth rate and the same initial density), maximum attenuation (the smallest possible 
future population density achievable, relative to a population with stable growth rate and the same initial density), fixed long-term amplification (amplified inertia) and fixed long-term attenuation (attenuated inertia).

These indices are standardised to remove the effects of asymptotic dynamics and to assume a total initial population density of 1, as recommended by Stott et al. (2011). Case-specific indices of transient dynamics and transient bounds are both valuable measures of transient dynamics, but it is important that both are comparable across models. Standardising the initial stage distribution so that overall population density is equal to 1 achieves this (Stott et al., 2011).

\section{Life table response experiment analysis}

The mortality of individuals was high for annual intervals 2010-2011 (159 individuals) and 2011-2012 (113 individuals). However, the annual interval 2013-2014 presented an extreme mortality of 382 individuals ( 219 adults and 138 juveniles). The matrix for the annual interval 2013-2014 was considered separately from the other years in the LTRE analysis. The contribution of each matrix element (cij) to the observed differences in $\lambda$ between the high mortality interval $(A 4)$ and other $(A 1, A 2$ or $A 3)$ years was performed with a fixed-design LTRE: $c i j=S i j(a i j-\bar{a} i j)$, in which $S i j$ was the sensitivity of the mean matrix between periods and $\bar{a} i j$ was an element of the mean matrix $(A m)$, calculated as $A m=(A 4+A) / 2 . A$ was one of the other matrices $(A 1$, $A 2$ or $A 3$ ) (Sampaio \& Scariot, 2010). When $S i j$ is positive, a negative value of $c i j$ indicates that the value of that vital rate in the bad year is lower than that in the good year, contributing to the observed decrease in $\lambda$.

We conducted the MPM analysis using the popbio package (Stubben \& Milligan, 2007) and the popdemo package for the transient dynamics analysis (Stott et al., 2012), both in the R statistical environment (R Development Core Team, 2015).

\section{RESULTS}

\section{Matrix population models and population dynamics}

The four annual transition matrices $(A 1, A 2, A 3$ and $A 4)$ based on life stages are shown in Table 1. A total of 717 individuals of Lychnophora ericoides were found in 2010, comprising 152 seedlings or saplings, 382 juveniles and 183 adults. The number of dead individuals was quite striking in the evaluation period (2010-2014), mainly in 2010-2011, 2011-2012 and 2013-2014. In 2014, more than 50\% of seedling or sapling, juvenile, and adult individuals showed mortality in the aerial part without resprouting. The number of recruited seedlings showed a sharp decline over time (Table 2).

The population growth rates $(\lambda)$ with $95 \%$ confidence intervals indicated a declining population in all periods from 2010 to 2014. The damping ratios also showed a declining trend over time (Table 3).

Using the sampled density in each life stage, it was not possible to compute the reactivity or amplification for any interval of time (2010-2011, 2011-2012, 2012-2013 
TABLE 1. Transition matrices of the Lychnophora ericoides population at Sucupira Farm, Brasília, Federal District, Brazil, during the study periods 2010-2011, 2011-2012, 2012-2013 and 2013-2014

\begin{tabular}{llll}
\hline \hline Period and life stage & Seedling or sapling & Juvenile & Adult \\
\hline 2010-2011 & & & \\
$\quad$ Seedling or sapling & 0.375 & 0.026 & 0.164 \\
$\quad$ Juvenile & 0.394 & 0.458 & 0.054 \\
$\quad$ Adult & 0.000 & 0.319 & 0.677 \\
2011-2012 & & & \\
$\quad$ Seedling or sapling & 0.374 & 0.036 & 0.067 \\
Juvenile & 0.293 & 0.454 & 0.063 \\
$\quad$ Adult & 0.000 & 0.316 & 0.831 \\
2012-2013 & & & \\
Seedling or sapling & 0.454 & 0.032 & 0.003 \\
Juvenile & 0.485 & 0.626 & 0.047 \\
$\quad$ Adult & 0.000 & 0.294 & 0.910 \\
2013-2014 & & & \\
$\quad$ Seedling or sapling & 0.324 & 0.000 & 0.006 \\
Juvenile & 0.000 & 0.156 & 0.033 \\
Adult & 0.000 & 0.073 & 0.315 \\
\hline \hline
\end{tabular}

TABLE 2. Population structure, seedling recruitment and number of dead individuals of Lychnophora ericoides at Sucupira Farm, Brasília, Federal District, Brazil, from 2010 to 2014

\begin{tabular}{lcccc}
\hline \hline Life stage & $2010-2011$ & $2011-2012$ & $2012-2013$ & 2013-2014 \\
\hline Seedling or sapling & 69 & 49 & 36 & 14 \\
Juvenile & 237 & 166 & 165 & 37 \\
Adult & 252 & 301 & 332 & 119 \\
Recruited seedlings & 30 & 17 & 1 & 2 \\
Dead & 159 & 113 & 22 & 382 \\
\hline \hline
\end{tabular}

TA B LE 3. Population growth rates $(\lambda)$, damping ratios $(\rho)$ and transient dynamics: reactivity $\left(\bar{\rho}_{1}\right)$, first-time step attenuation $\left(\rho_{1}\right)$, maximum amplification $\left(\bar{\rho}_{\text {max }}\right)$, maximum attenuation $\left(\rho_{\max }\right)$ and upper $(\bar{\rho} \infty)$ and lower $(\rho \infty)$ inertia in a population of Lychnophora ericoides in Brasília, Federal District, Brazil*

\begin{tabular}{lllllllll}
\hline \hline Period & $\lambda\left(\mathrm{CI}_{95 \%}\right)$ & $(\rho)$ & $\bar{\rho}_{1}$ & $\underline{\rho}_{1}$ (bias) & $\bar{\rho}_{\max }$ & $\underline{\rho_{\max }}$ & $\bar{\rho} \infty$ & $\underline{\rho} \infty$ \\
\hline $2010-2011$ & $0.84(0.71-1.06)$ & 2.21 & 1.060 & $0.970(0.911)$ & 1.098 & 0.802 & 1.096 & 0.802 \\
$2011-2012$ & $0.90(0.85-0.97)$ & 2.38 & 1.062 & $0.937(0.737)$ & 1.118 & 0.454 & 1.118 & 0.454 \\
$2012-2013$ & $0.96(0.94-0.98)$ & 1.49 & 1.001 & $0.996(0.979)$ & 1.005 & 0.937 & 1.005 & 0.937 \\
$2013-2014$ & $0.33(0.30-0.46)$ & 1.01 & 1.076 & $0.946(0.985)$ & 2.224 & 0.000 & 2.224 & 0.000 \\
\hline
\end{tabular}

*The first-time step attenuation was calculated using the natural vector of population density and using the biased vector (just seedlings or saplings). The other parameters were calculated using the biased vector of density, and the initial condition imposed was just seedlings or adults (see Stott et al., 2012, for details). 
TA B LE 4. Elasticity analysis for Lychnophora ericoides at Sucupira Farm, Brasília, Federal District, Brazil, during the study periods 2010-2011, 2011-2012, 2012-2013 and 2013-2014*

\begin{tabular}{llll}
\hline \hline Period and life stage & Seedling or sapling & Juvenile & Adult \\
\hline 2010-2011 & & & \\
$\quad$ Seedling or sapling & 0.071 & 0.007 & 0.082 \\
$\quad$ Juvenile & 0.089 & 0.143 & 0.032 \\
$\quad$ Adult & 0.000 & 0.114 & 0.461 \\
2011-2012 & & \\
$\quad$ Seedling or sapling & 0.019 & 0.003 & 0.024 \\
Juvenile & 0.027 & 0.070 & 0.041 \\
Adult & 0.000 & 0.066 & 0.749 \\
2012-2013 & & & \\
Seedling or sapling & 0.006 & 0.004 & 0.003 \\
Juvenile & 0.007 & 0.089 & 0.040 \\
$\quad$ Adult & 0.000 & 0.043 & 0.806 \\
2013-2014 & & & \\
$\quad$ Seedling or sapling & 0.359 & 0.003 & 0.010 \\
Juvenile & 0.013 & 0.032 & 0.024 \\
Adult & 0.000 & 0.034 & 0.525 \\
\hline \hline
\end{tabular}

*Each value represents the contribution to the dominant eigenvalue $(\lambda)$.

and 2013-2014). Using sampled density, the first-time attenuation for all intervals ranged from 0.937 to 0.996 (Table 3 and Fig. 3), suggesting that the population would decrease by $93.7 \%$ within the span of one time period. When the populations were dominated by adults $(\mathrm{S}=0, \mathrm{~J}=0$ and $\mathrm{A}=1)$, we found that reactivity (Table 3) and population could increase by $7.6 \%$ to less than $0.1 \%$. However, using the same condition (i.e. only adults), we found that the maximum amplification in density would be from $9.8 \%$ to $222.4 \%$ in the transient period. On the other hand, when the population had as its initial condition just seedlings, the maximum attenuation $(\mathrm{S}=1, \mathrm{~J}=0$ and $\mathrm{A}=0)$ was a reduction in density from $6.3 \%$ to total population extinction (Table 3 and Fig. 3). However, the first-time attenuation using over-represented seedlings or saplings $(\mathrm{S}=1, \mathrm{~J}=0$ and $\mathrm{A}=0$ ) suggested that the population could be reduced to $73.7 \%$ in just one period (Fig. 3).

Considering the four matrices, the stochastic population growth rate was $<1$ with value $\lambda=0.358$ and $\mathrm{CI}_{95 \%}=(0.354-0.362)$, indicating a sharp decline in the population of Lychnophora ericoides in the study area. Elasticity analyses indicated that stasis of adult individuals $(46-80 \%)$ contributed most to population growth rate (Table 4).

An extinction probability of $100 \%$ for the population was predicted for approximately 15 years (Fig. 4), assuming continuous anthropic disturbances in the area.

According to the LTRE results, the low value of $\lambda$ in the high-mortality year was caused by lower stasis of seedlings or saplings, besides the fecundity of adults and retrogression of juvenile and adults (Fig. 5). 

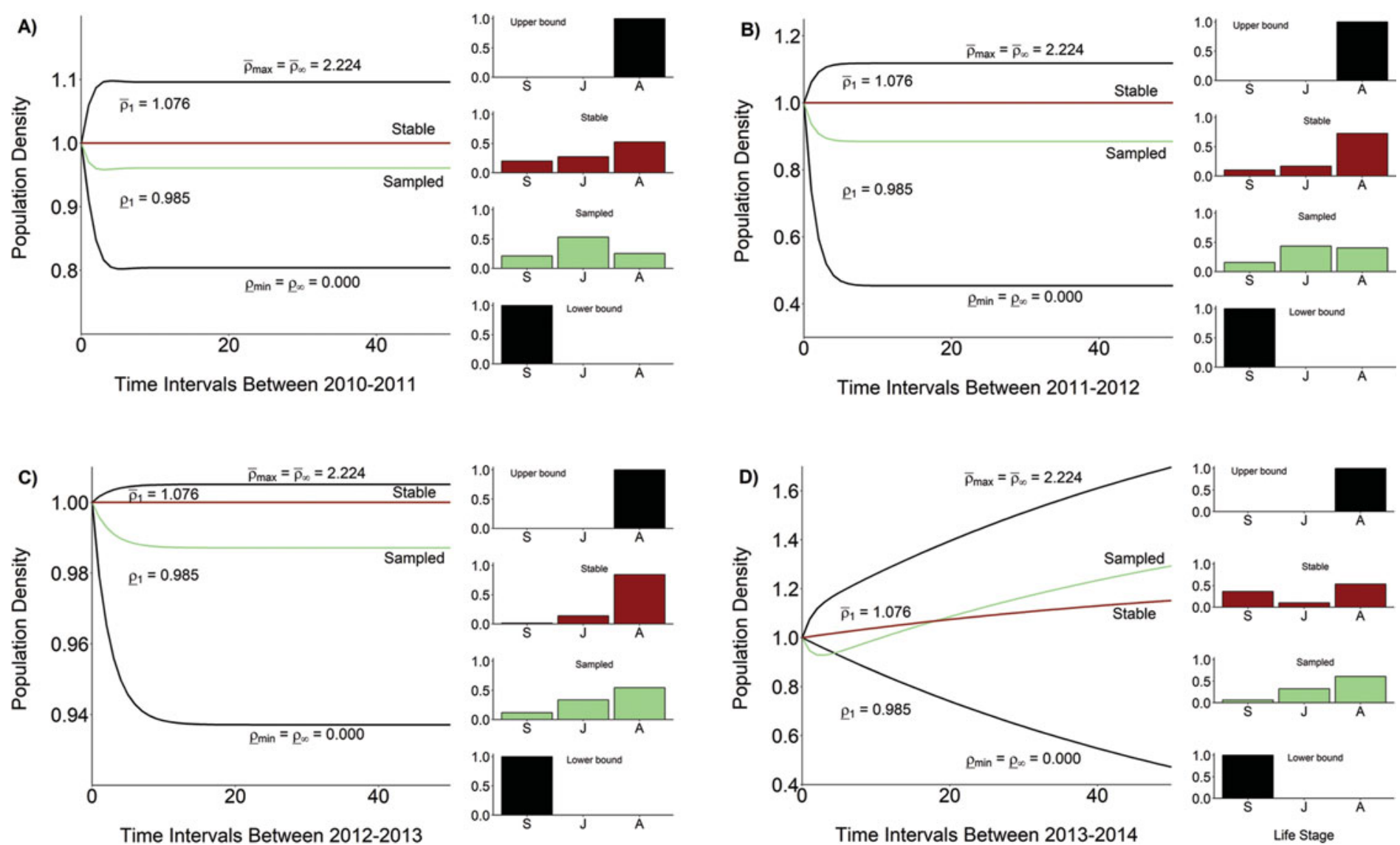

FIg. 3. Standardised transient dynamics in a population of Lychnophora ericoides in Brasília, Federal District, Brazil, and demographic distribution scaled to an initial population density sum 1. Black bars in the demographic distribution represent the biased distribution [lower boundary in which seedling $(S)=1$, juvenile $(\mathrm{J})=1$ and adult $(\mathrm{A})=1$; upper boundary in which $\mathrm{S}=0, \mathrm{~J}=0$ and $\mathrm{A}=1]$. The green bars show the sampled distribution at each time interval, and red bars indicate stable distribution. Time intervals: A, 2010-2011; B, 2011-2012; C, 2012-2013; D, 2013-2014. For all intervals, the first-time attenuation $\left(\rho_{1}\right)$ was calculated using the over-representation of seedlings; however, in the interval 2013-2014, $\rho_{1}$ should be calculated using the over-representation of juveniles $(\mathrm{S}=0, \mathrm{~J}=1$ and $\mathrm{A}=0)$, with the result equal to 0.696 . 


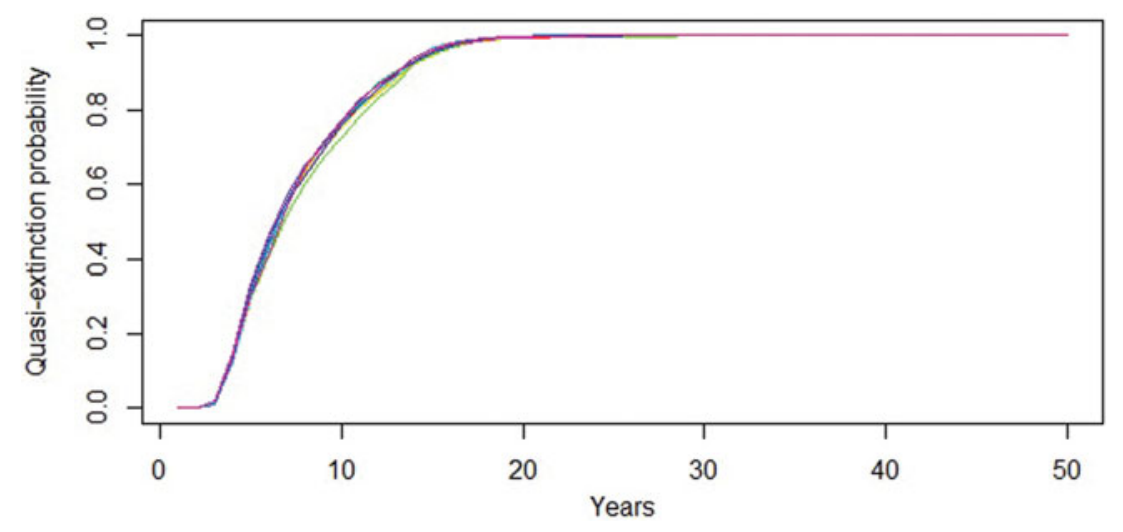

FIG. 4. Probability of local extinction for a population of Lychnophora ericoides in Brasília, Federal District, Brazil, based on transition matrices (2010-2011, 2011-2012, 2012-2013 and 2013-2014).
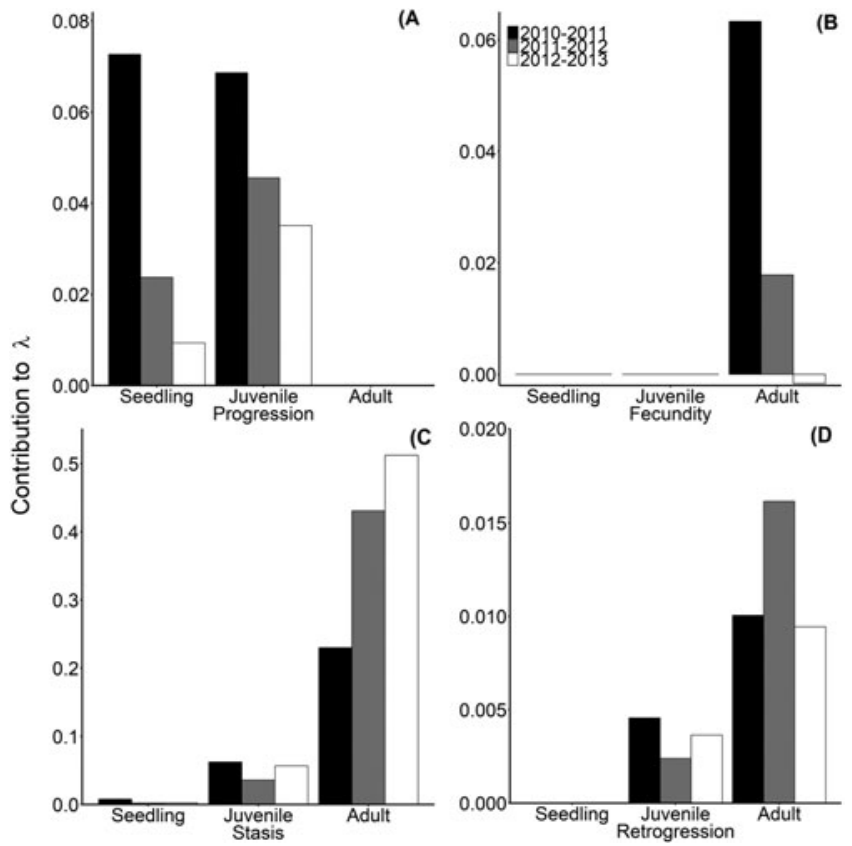

FIG. 5. Results of a life table response experiment, showing contributions of growth (A), fecundity (B), stasis (C) and retrogression (D) to the difference in annual population growth rate between the high-mortality year (2013-2014) and other years (2010-2011, 2011-2012 and 2012-2013) for Lychnophora ericoides at Sucupira Farm, Brasília, Federal District, Brazil. Note that the scale of the $y$-axes differs between panels. 

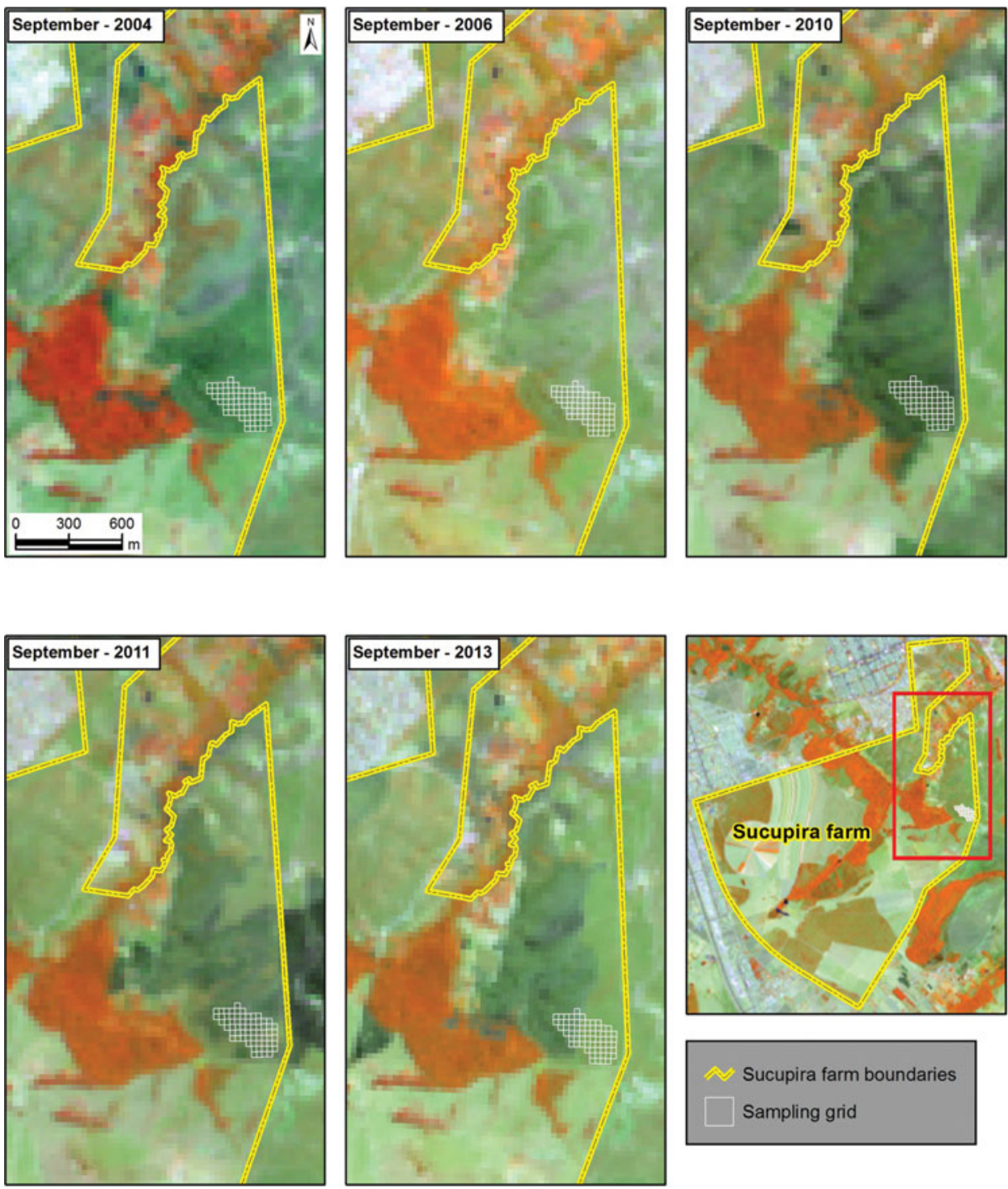

FIG. 6. Locations of fire occurrences, obtained from LandSat images (TM 5, 7 ETM and 8 OLI) with false-color composition R4G5B3 (Landsat TM 5 and ETM 7) and R5G6B4 (Landsat 8 OLI), at Sucupira Farm, Brasília, Federal District, Brazil. Fire scars are represented by the dark areas.

\section{Fire regime and rainfall}

The satellite images showed that the sampling area has had a high frequency of fire (2004, 2006, 2010, 2011 and 2013) (Fig. 6). Fire occurrences were mainly in September, at the end of the dry season. This evidence indicates that the entire population of Lychnophora ericoides at Sucupira Farm has been under fire threat for more than 10 
years. During the study period (2010-2014), this area burned in 2010, 2011 and 2013. Although the area burned in 2013, some plots were not affected.

The total precipitation values in the study area were $1267 \mathrm{~mm}(2010), 1416 \mathrm{~mm}$ (2011), $1332 \mathrm{~mm}$ (2012) and $1600 \mathrm{~mm}$ (2013).

\section{DISCUSSION}

The pattern of high fire frequency in the late dry season (August to September) observed in the study area may be favorable for some herbaceous and shrub species of the Cerrado vegetation and open physiognomies (Miranda et al., 2002) because it causes high mortality of woody species (Medeiros \& Miranda, 2005). The number of dead or vanished individuals was very high in 2010-2011 (159) and 2011-2012 (113). Subsequently, this number dropped in 2012-2013 (22). However, an intense increase in dead or vanished individuals (382) was observed in 2013-2014. All the high-mortality years were years with fire. Furthermore, because there was no fire in 2012, a higher biomass could have accumulated in the area, causing a stronger fire in 2013 that could have led to higher mortality of Lychnophora ericoides.

Severe variability in precipitation patterns has been a cause of high mortality of woody species in the Brazilian semi-arid north-eastern region (Baldauf et al., 2015). However, our study area in Central Brazil does not exhibit this type of severe variation in precipitation patterns; Baldauf et al., (2015) observed variations of 50\% in precipitation patterns throughout 3 years. Furthermore, the total precipitation showed some increase in the 2013 period, the year of severe mortality for Lychnophora ericoides.

In tropical adult trees without damage or individual death caused by harvesting or other disturbances, such as disease and fire, stasis is high and comprises a large amount of the observed elasticity (Kroon et al., 2000). Most of the proportional changes in population growth rate are caused by changes in growth and survival rates (Franco \& Silvertown, 2004; Bruna et al., 2009). Results of the elasticity analysis indicated this type of pattern for Lychnophora ericoides, with stasis of the adult stage contributing significantly to population decline. Furthermore, the results of the LTRE analysis indicated low stasis of seedlings or saplings, as well as fecundity of adults and retrogression of juvenile and adults, as the main factors for the low value of $\lambda$ during the period of extreme mortality of individuals (2013-2014). Despite the observed harvesting activities of Lychnophora ericoides, we did not have enough data or control plots to associate the population decline with this kind of human disturbance.

The results of transient dynamics complemented the dataset that indicates a local extinction trend for this Lychnophora ericoides population. Combining asymptotic and transient dynamics creates a clear perspective of possible population changes (Raventós et al., 2015, Tremblay et al., 2015). The declining trends of the damping ratios from 2010 to 2014 are the expected results of mortality that reached high levels in 2013-2014, in turn indicating the low resilience of this population (Stott et al., 2011). The other transient indices also showed that the population is much less likely 
to have increases in density compared with reduction for all intervals from 2010 to 2014.

The prediction that disturbances occurring frequently in Cerrado remnants would have negative effects on the population growth rates of Lychnophora ericoides was verified, because high-mortality years were years with fire. Education of the local population should be undertaken to rescue this vulnerable population of Lychnophora ericoides. Also, a number of actions could be taken for sustainable management for Lychnophora ericoides, including, for example, the establishment of an agreement between the parties involved in resource usage (Dietz et al., 2003). This agreement should consider the ecological needs for population maintenance and define the boundaries of resources and user groups, as well as establish an arbitration and mediation mechanism to resolve conflicts.

\section{ACKNOWLEDGEMENTS}

The authors acknowledge the Instituto Chico Mendes de Conservação da Biodiversidade for the scientific initiation grant to Hannah Menezes. The authors would like to thank Washington L. Oliveira, Isabella L. P. Lima, Pamela Moser and Hannah Menezes for field assistance. The first author also thanks the Fundação de Amparo à Pesquisa do Distrito Federal.

\section{REFERENCES}

Almeida, S. P., Proença, C. E. B, Sano, S. M. \& Ribeiro, J. F. (1998). Cerrado: Espécies Vegetais Úteis. Planaltina: Embrapa-CPAC.

Avelino, A. S. (2005). Biologia reprodutiva de Lychnophora ericoides Mart. (Asteraceae: Vernonieae). Master's dissertation, Universidade de Brasília.

Baldauf, C., Corréa, C. E., Ferreira, R. C. \& Santos, F. A. N. (2015). Assessing the effects of natural and anthropogenic drivers on the demography of Himatanthus drasticus (Apocynaceae): implications for sustainable management. Forest Ecol. Managem. 354: 177-184.

Benites, V. M. (2001). Caracterização de solos e de substâncias húmicas em áreas de vegetação rupestre de altitude. Doctoral thesis, Universidade Federal de Viçosa.

Benites, V. M., Schaefer, C. E. G. R., Simas, F. N. B. \&Santos, H. G. (2007). Soils associated with rock outcrops in the Brazilian mountain ranges Mantiqueira and Espinhaço. Revista Bras. Bot. 30(4): 569-577.

Ber nal, R. (1998). Demography of the vegetable ivory palm Phytelephas seemannii in Colombia, and the impact of seed harvest. J. Appl. Ecol. 35(1): 64-74.

Bruna, E. M., Fiske, I. J. \& Trager, M. D. (2009). Habitat fragmentation and plant populations: is what we know demographically irrelevant? J. Veg. Sci. 20(3): 569-576.

Ca S Well, H. (2001). Matrix Population Models: Construction, Analysis and Interpretation. Sunderland, Massachusetts: Sinauer Associates.

Collevatti, R. G., Rabelo, S. G, \& Vieira, R. F. (2009). Phylogeography and disjunct distribution in Lychnophora ericoides (Asteraceae), an endangered cerrado shrub species. Ann. Bot. 104(4): 655-664.

Dietz, T., OStrom, E. \& STER N, P. C. (2003). The struggle to govern the commons. Science 302(5652): 1907-1912. 
ES R I (2008). ArcGIS 10.1. Redlands, California: Environmental Systems Resource Institute.

Franco, M. \& Silvertown, J. (2004). A comparative demography of plants based upon elasticities of vital rates. Ecology 85(20): 531-538.

Gadue, O. G. \& Tick TIN, T. (2010). Effects of harvest of nontimber forest products and ecological differences between sites on the demography of African mahogany. Conservation Biol. 24(2): 605-614.

Giroldo, A. B \& SCARiot, A. (2015). Land use and management affects the demography and conservation of an intensively harvested Cerrado fruit tree species. Biol. Conservation 191: $150-158$.

Gotts berger, G. \& Silberbauer-Gottsberger, I. (2006). Life in the Cerrado, a South American Tropical Seasonal Ecosystem: Origin, Structure, Dynamics and Plant Use. London: Springer-Verlag.

Holm, J. A., Miller, C. J. \& Cropper, W. P. (2008). Population dynamics of the dioeceus Amazonian palm Mauritia flexuosa: simulation analysis for sustainable harvesting. Biotropica 40(5): 550-558.

Instituto Nacional de Meteorologia (continuously updated). Inmet database. Online. Available: http://www.inmet.gov.br/portal/

Kroon, H., Groenendael, J. \& Eherlen, J. (2000). Elasticities: a review of methods and model limitations. Ecology 81(3): 607-618.

LEFKOVITCH, L. T. (1965). The study of population growth in organisms grouped by stages. Biometrics 21(1): 1-18.

Medeiros, M. B. \& Miranda, H. S. (2005). Mortalidade pós-fogo em espécies lenhosas de campo sujo submetido a três queimadas prescritas anuais. Acta Bot. Brasil. 19(3): 493-500.

Miranda, H. S., Bustamante, M. C. M. \& Miranda, A. C. (2002). The fire factor. In: Oliveira, P. S. \& M A Rquis, R. J. (eds) The Cerrados of Brazil: Ecology and Natural History of a Neotropical Savanna, pp. 51-68. New York, New York: Columbia University Press.

Morris, W. F. \& Doak, D. F. (2002). Quantitative Conservation Biology: Theory and Practice of Population Viability Analysis. Sunderland, Massachusetts: Sinauer Associates.

Portela, R. C. Q., Bruna, E. M. \& Santos, F. A. M. (2010). Demography of palm species in Brazil's Atlantic Forest: a comparison of harvested and unharvested species using matrix models. Biodivers. \& Conservation 19(8): 2389-2403.

R Development Core Team (2015). R: a Language and Environment for Statistical Computing. Vienna: R Foundation for Statistical Computing.

Raventós, J., Gonzalez, E., Mujica, E. \& Bonet, A. (2015). Transient population dynamics of two epiphytic orchid species after Hurricane Ivan: implications for management. Biotropica 47(4): 441-448.

Ribeiro, J. F. \& WALter, B. M. T. (2008). As principais fitofisionomias do Bioma Cerrado. In: Sano, S. M., Almeida, S. P. \& Ribeiro, J. F. (eds) Cerrado: Ecologia e Flora, pp. 153-212. Brasília: Embrapa Cerrados and Embrapa Informação Tecnológica.

SAmpaio, M. \& SCARIOT, A. (2010). Effects of stochastic events on population maintenance of an understorey palm species (Geonoma schottiana) in riparian tropical forest. J. Trop. Ecol. 26(2): 151-161.

Schmidt, I. B., Mandle, L., Ticktin, T. \& Gaoue, O. G. (2011). What do matrix population models reveal about sustainability of non-timber forest product harvest? J. Appl. Ecol. 48(4): 815-826.

Semir, J., Rezende, A. R., Monge, M. \& Lopes, N. P. (2011). As Arnicas Endêmicas das Serras do Brasil - Uma Visão Sobre a Biologia e a Química das Espécies de Lychnophora (Asteraceae). Ouro Preto: Universidade Federal de Ouro Preto. 
Silva, D. (2005). Estrutura populacional, fenologia, crescimento e efeito de poda em Lychnophora ericoides Mart. (Asteraceae). M.Sc. dissertation, Universidade de Brasília.

Silva, F. A. M., Assad, E. D. \& Evangelista, B. A. (2008). Caracterização climática do bioma Cerrado. In: Sano, S. M., Almeida, S. P. \& Ribeiro, J. F. (eds) Cerrado: Ecologia e Flora, pp. 70-88. Brasília: Embrapa Cerrados and Embrapa Informação Tecnológica.

Stanley, D., Voeks, R . \& Short, L. (2012). Is non-timber forest product harvest sustainable in the less developed world? A systematic review of the recent economic and ecological literature. Ethnobiol. Conserv. 1(9): 1-39.

Stott, I., Townley, S. \& Hodgson, D. J. (2011). A framework for studying transient dynamics of population projection matrix models. Ecol. Letters 14(9): 959-970.

Stot t, I., Townley, S. \& Hodgson, D. J. (2012). popdemo: an R package for population demography using projection matrix analysis. Methods Ecol. Evol. 3(5): 797-802.

Stubien, C. \& Milligan, B. (2007). Estimating and analyzing demographic models using the popbio package in R. J. Statist. Softw. 22(11): 1-27.

TIC K TIN, T. (2004). The ecological implications of harvesting non-timber forest products. $J$. Appl. Ecol. 41(1): 11-21.

Ticktin, T. Nantel, P., Ramirez, F. \& Johns, T. (2002). Effects of variation on harvest limits for nontimber forest species in Mexico. Conservation Biol. 16(3): 691-705.

Ticktin, T., Ganesan, R., Paramesha, M . \& Setti, M. (2012). Disentangling the effects of multiple anthropogenic drivers on the decline of two tropical dry forest trees. $J$. Appl. Ecol. 49(4): 774-784.

Tremblay, R. L., Raventós, J. \& Ackerman, J. D. (2015). When stable-stage equilibrium is unlikely: integrating transient population dynamics improves asymptotic methods. Ann. Bot. 116(3): 381-390.

United States Geological Service (2015). EarthExplorer. Online. Available: http://earthexplorer.usgs.gov

VAsquez, R . \& Gentry, A. H. (1989). Use and misuse of forest-harvested fruits in the Iquitos area. Conservation Biol. 3(4): 350-361.

Zuidema, P. A. \& Boot, R. G. (2002). Demography of the Brazil nut tree (Bertholletia excelsa) in the Bolivian Amazon: impact of need extraction on recruitment and population dynamics. J. Trop. Ecol. 18(1): 1-31.

Received 20 March 2017; accepted for publication 23 June 2017; first published online 25 July 2017 